\title{
EDITORIAL
}

\section{Does control of rheumatic disease raise the standard of living in developing countries?}

\author{
Richard Wigley $\cdot$ Arvind Chopra $\cdot$ Simon Wigley • \\ Arzu Akkoyunlu-Wigley
}

Received: 5 February 2009 /Accepted: 9 February 2009 /Published online: 3 March 2009

(C) Clinical Rheumatology 2009

The WHO-ILAR collaborative program on rheumatic disease (COPCORD) includes all musculoskeletal disease (RD). Studies have now been completed in many developing countries, and a number of population samples have been studied in China, India, the Philippines, and Iran [1]. These have shown that low back pain, knee, neck, and arm pain are the most common $\mathrm{RD}$ as is also the case in developed countries [2]. Knee osteoarthritis is a major problem, whereas hip osteoarthritis is rare. Rheumatoid arthritis prevalence in developing countries is about half that of developed countries. In Han Chinese, osteoarthritis knee and low back pains are more common in north China than in the south and in migrants in Malaysia near the equator [3]. This is paralleled by radiological changes, so it is not simply explained by increased pain sensitivity to cold.

World Health Organization estimates of the burden of disease expressed as disability adjusted life years (DALYS)

R. Wigley $(\bowtie)$

240 Park Road,

Palmerston North, New Zealand

e-mail: r.d.wigley@xtra.co.nz

A. Chopra

Centre for Rheumatic Diseases,

1988 Convent St, Camp,

Pune 411001, India

S. Wigley

Department of Philosophy, Bilkent University,

06800 Ankara, Turkey

A. Akkoyunlu-Wigley

Department of Economics, Hacettepe University,

06532 Ankara, Turkey are summarized by Brooks [2]. DALYS are the sum of disability years lost due to disability and years of life lost due to mortality, so DALYS would underestimate the relative burden of low mortality disorders such as RD. Thus, RD deserves a much higher priority than currently recognized by $\mathrm{WHO}$ and in many national health plans. RD is the most prevalent category of disease in the Bighwan COPCORD study [4]. This study is unique, as it has been continued prospectively for 12 years with sustained efforts to improve the prevention, control, and care of RD.

A great deal of information has accumulated in the COPCORD studies. Though this would have been used locally to promote health care for $\mathrm{RD}$, it is now necessary to take an overview of the data with respect to all developing countries. We have no COPCORD data from Sub-Saharan Africa where the problems are formidable and resources are minimal.

There is an increasing opportunity for the prevention of $\mathrm{RD}[5,6]$. This will depend mainly on education, which should cost less than treatment and rehabilitation.

The major question now is how to raise the level of control of RD in a cost-effective manner, bearing in mind the limited economic and skill resources of developing countries. Chronic disabling conditions impair ability to progress in education and to be efficient in the work force and require support from fit members of society, as with care of the aged. This has been demonstrated by economists $[7,8]$. They argue that an increase in life expectancy as a result of exogenous health interventions means that more people must share a limited supply of resources. Doubling life span could mean that double the number would have to share the limited amount of food with a decrease in health, economic level, and a rise in poverty. Contrary to expect- 
ations, they found that the control of fatal diseases, by increasing population, especially the aged, reduces per capita income.

By contrast, control of usually non-fatal chronic disabling disease can have a positive impact on average income. This has been demonstrated with the control of hookworm [9] and with malaria [10].

By analogy, it would be expected that control of RD would also raise the standard of living and improve overall productivity and quality of life without increasing the population. To test this hypothesis, it is planned to compare available economic indicators in Bhigwan village in India before and after 12 years of intervention against RD. A comparison would also be made with the contemporaneous economic status in a similar village where there has been no such intervention.

Obviously control of other diseases, particularly infections, will have to continue. Welfare support in food and finance has only a temporary effect and may not reach the most disadvantaged but will still be needed as well as efforts to control population expansion in developing countries.

\section{References}

1. Chopra A (2008) Epidemiology of rheumatic musculoskeletal disorders in the developing world. Best Pract Res Clin Rheumatol 22:583-604

2. Brooks PM (2006) The burden of musculoskeletal disease: a global perspective. Clin Rheumatol 25:778-781

3. Wigley RD (2003) Rheumatic disease in Han Chinese. What have we learned from 19 years of epidemiological study. J Rheumatol 30:2009-2010

4. Chopra A, Saluja M, Patil J, Tandale H (2002) Pain and disability, perceptions and beliefs of a rural Indian population. J Rheumatol 29:614-621

5. Wigley RD (ed) (1994) Primary prevention of rheumatic disease. Parthenon, Carnforth

6. Wolfe AD, Brooks P, Akesson K, Mody GM (2008) Prevention of musculoskeletal conditions in the developing world. Best Pract Res Clin Rheumatol 22:759-772

7. Acemoglu D, Johnson S (2005) Disease and development: the effect of life expectancy on economic growth. J Polit Econ 115:925-985

8. Ashraf, QH, Lester A, Weil, DN (2008) When does improving health raise GDP? NBER Working Paper Series no. 14449

9. Bleakley H (2007) Disease and development: evidence from hookworm eradication in the American South. Q J Econ 122:73117

10. Bleakley H (2007) Malaria eradication in the Americas: a retrospective analysis of childhood exposure. http://home.uchicago.edu/ bleakley/Bleakley_Malaria_August2007.pdf. Cited 17 August 2007 